\title{
Impact Prognostic of Delayed Reperfusion Time in Patients With Stemi of $\leq 24$ Hours Treated in the Emergency Department of a General Hospital
}

Lorenzo Socias ( $\sim$ lsocias3@gmail.com )

Intensive Medicine Department. Son Llàtzer University Hospital . Palma-Manacor road, km 4. 07198.

Palma Mallorca.

Guillem Frontera

Hospital Son Llatzer

Catalina Rubert

Hospital Son Llatzer

Joan Torres

Hospital Son Llatzer

Tomas Ripoll

Hospital Son Llatzer

Marcos Pascual

Hospital Universitario Son Espases: Hospital Universitari Son Espases

Andres Carrillo

Hospital Universitario Miguel Servet

Vicente Peral

Hospital Universitario Son Espases: Hospital Universitari Son Espases

Miquel Fiol

Hospital Universitario Son Espases: Hospital Universitari Son Espases

\section{Original Research}

Keywords: Acute coronary syndrome with ST elevation, Acute myocardial infarction, Infarction Code, Care program, Mortality

Posted Date: September 21st, 2020

DOI: https://doi.org/10.21203/rs.3.rs-76105/v1

License: (c) (i) This work is licensed under a Creative Commons Attribution 4.0 International License.

Read Full License 


\section{Abstract}

Background. The patients who attend a hospital without a hemodynamic laboratory may have differences in health outcomes, treatment, reperfusion times, the rate of cardiovascular complications, hospital stay, mortality or costs may be affected. The study aimed to analyze the prognostic of patients with STEMI treated in the Emergency Department (ED) and the impact prognostic of the delayed reperfusion time in a Hospital General without hemodynamic laboratory.

Methods. After ethics review board approval, this retrospective observational cohort study of patients included acute coronary syndrome with ST elevation of $\leq 24 \mathrm{~h}$ in the Illes Balears infarction code registry (Cl-IB) between May 2008 and December 2018. The information recorded were age, sex, cardiovascular risk factors, site of AMI, time delays, reperfusion therapy with fibrinolysis and primary angioplasty (PA). Cardiovascular Event (CE) was defined the combined variable: Killip class progression, malignant arrhythmias, Re-infarction, cerebrovascular disease and mortality.

Results. 605 patients were analyzed. The reperfusion treatment was $83,1 \%(80,8 \%$ with PA). $19 \%$ presented some CE. Hospital and monthly mortality was $6.8 \%$ and $7.8 \%$ respectively. The main differences between patients with and without CE were: age (66 vs 59 years); Chronic obstructive pulmonary disease (COPD); previous infarction; anterior location; Door-To-Needle Time and FPC-PA time. The risk factors of CE were: age, COPD, anterior location, fibrinolysis and patients without reperfusion treatment. In the group with PA, the risk of mortality was higher in COPD $(p=0.012)$, Symptom start -FPC time with $(p=0,084)$ and FPC-PA time $>90$ minutes $(p=0.107)$. FCM-AP> 90 minutes had a higher mortality (10 vs $4.4 \% ; H R$ 1,79; IC 95\% 1,15-2,78; log-rank:p=0,013)

Conclussions. In our cohort, most patients received reperfusion treatment and were performed within the recommended time. In ED, the pacients with a FCM-PA time longer than recommended in the guidelines and COPD had higher CE y mortality.

\section{Background}

In March 2008, the Balearic Islands Infarct Code (Cl-IB $)^{1}$ assistance program was began in the Balearic Islands. The data were published in $2016^{2}$. The Hospital Universitary Son Llàtzer (HUSLL) is a secondlevel university hospital, it does not have a hemodynamic laboratory and patients with ST-segment elevation acute myocardial infarction (STEMI) are referred to other hospital with laboratory (Hospital University Son Espases) to practice primary angioplasty (PA). The patients who attend a hospital without a hemodynamic laboratory may have differences in health outcomes, treatment, reperfusion times, the rate of cardiovascular complications, hospital stay, mortality or costs may be affected ${ }^{3}$.

The objective of our work is to analyze the prognostic of patients with STEMI treated in the Emergency Department (ED) and the impact prognostic of the delayed reperfusion time. 


\section{Methods}

\section{Study design and setting}

This is a retrospective cohort study from March 8, 2008 to December 31, 2018, which included 605 patients, included in the $\mathrm{CI}-\mathrm{IB}$, treated alive with a diagnosis of STEMI less than 24 hours from the start of the symptoms until first medical contact (FCM). The study was conducted at Emergency Department of Hospital Universitario Son Llàtzer of Palma Mallorca, Baleares Island, Spain.

\section{Data Collection}

The main variables were analyzed were demographic (age, sex, cardiovascular risk factors), clinical (location, Killip grade at admission and worse Killip during admission) and reperfusion treatment (fibrinolysis and primary angioplasty). The main time intervals analyzed were: Time from the onset of symptoms-FCM, time from the FCM to fibrinolysis (door-to-needle time) and time from FCM-to the start of primary angioplasty (door-to-balloon time). The latter was also represented as a binary variable ( $\leq 90$ minutes) given that they are the recommendations of the STEMI guidelines in patients with primary interventionism ${ }^{4}$. Two population groups were stratified according to whether or not had a cardiovascular event (CE). The combined variable was defined as CE: reinfarction during the stay, stroke, malignant arrhythmia (ventricular fibrillation and sustained ventricular tachycardia, and worse Killip during admission).

\section{Satatistical analysis}

A descriptive analysis of the variables was performed, calculating the median with its interquartile range (IQR) for the quantitative variables and frequencies and percentages for the qualitative ones. For hypothesis testing, the Student's t test, the Mann-Whitney $U$ test and the chi-square test / Fisher's exact test were used, respectively. A multivariate analysis was performed using a Cox proportional hazards model to study the relationship of demographic and clinical variables, time intervals, and all potential confounders with cardiovascular events during hospital stay and 30-day mortality. Differences were considered statistically significant if the $p$ value was less than 0.05 . IBM ${ }^{\circledR}$ SPSS ${ }^{\circledR}$ Statistics v. 22.0.

\section{Results}

605 patients with STEMI were included. Table 1 shows the main results. Reperfusion was $85.9 \%$, (77.2\% PA). $19 \%$ had some CE. Hospital and month mortality was $6.8 \%$ and $7.8 \%$, respectively. The independent risk factors for CE were: age, COPD, anterior location, fibrinolysis, and patients without revascularization (See Table II). In patients where an invasive strategy was decided, the independent risk factors for mortality at 30 days were COPD (HR: 2.934; $p=0.012$ ), time onset of symptoms-PCM (HR: 1.001; $p=$ 0.003) and time PCM-AP> 90 minutes (HR: 1.835; $p=0.084$ ) (see table III). Thus, the 30-day mortality in patients with PCM-ICP ARI time> 90 min was $10 \%$ compared to $4.4 \%$ for those treated before 90 min (HR 1.79; $95 \%$ Cl 1.15 -2.78; log-rank: $p=0.013$ ) (Figure 1). 


\section{Discussion}

The results of this cohort study show the favorable evolution of the implementation of the AMI code in patients in our district. Although in our island the distances are not very long, a large part of the population was diagnosed in the Emergency Department (ED) at the beginning of the implantation. Once the initial phase of implementation was over, the referral of patients to reference hospital was modified with the intention of guarantee a homogeneous care of the population with greater efficiency of out-ofhospital activation of PA. In our cohort, previous infarction and COPD are more prevalent in the group of patients with CE. A relevant aspect in our study is that COPD is an independent risk factor for mortality. Both COPD and its exacerbation are associated with acute myocardial infarction. These patients frequently present atypical symptoms, delay in the diagnosis of $\mathrm{AMI}$, undertreatment and higher mortality 5,6 .

A large percentage of patients treated at our center are treated within adequate time intervals. Some studies suggest that the cut-off point at which PA is not higher than fibrinolysis is approximately 2 hours, depending on the duration of ischemia, the size of the myocardium at risk, and the risk of bleeding. Our results demonstrate a fibrinolytic treatment according to the standards with a gate-to-needle time $<30$ minutes ${ }^{7,8}$.

The incidence of PA is usually lower in hospitals without hemodynamics ${ }^{3}$. In our study, patients who underwent an invasive strategy from the ED presented less CE. We observed that although there was an increase in PA from the beginning of the infarction code, we present a slightly higher percentage of patients without reperfusion in other studies ${ }^{8}$.

The time delay between the appearance of heart attack symptoms and the performance of angioplasty is a very important factor in prognosis. The greater this delay, the greater the injury that occurs. The data published from population registries show that easy access to a hospital with hemodynamics is associated with an increase of the its use, a decrease in the delay in care and lower mortality ${ }^{9,10,11}$. It is clear that the distance to the center with hemodynamic availability is important to achieve optimal times $^{12}$ Long transport distances and the lack of initial access to hospitals without hemodynamic availability have been related to prognosis ${ }^{13,14}$. In our registry, the symptoms onset-FCM time and the FCM-AP time were longer in patients with COPD. Furthermore, these delays were associated with inhospital and 1-month mortality. In our city, the distances between the two hospitals are not long, so we must evaluate other circumstances such as the patient going directly to the ED, the delay in diagnosis, and the waiting time for medicalized transport for the transfer. This requires continuous evaluation and critical analysis of the results to optimize existing care networks.

\section{Study Limitations}

The main limitation of our study is the limited number of patients and that it is from a single center. Other limitations were the absence of information in some more specific times in relation to the logistics of 
transfers and hours of activation of the out-of-hospital Medical Services.

\section{Conclusions}

As conclusions, we highlight that despite the fact that distances are short in our community, delay times are an important factor in the prognosis of patients, both onset of symptoms-FCM and in the delay in access to the hemodynamic room. The analysis suggests that patients diagnosed with COPD could increase mortality.

\section{Abbreviations}

ED: Emergency Departmen

STEMI. ST-segment elevation myocardial infarction

Cl-IB. Code Infarction- Illes Balerars

AMI. Acute Myocardial infarction

Angioplasty Primary

CE.Cardiovascular Event

FCM. First Primary Contact Medical

IQR. Interquartil range

COPD. chronic obstructive pulmonary disease

Confidence interval

HR: Hazard ratio

\section{Declarations}

\section{Acknowledgments}

Research group CI-IB: Miquel Fiol, Armando Bethencourt, Andrés Carrillo, Carlos Fernandez Palomeque, Vicente Peral, Alberto Rodríguez, Cristina Royo, Mireia Ferreruela, Alfredo Gómez, Rosa González, Marcos Pascual, Mar Alameda (Hospital Universitario Son Espases); Catalina Rubert, Lorenzo Socias, Catalina Forteza, Joan Torres, Tomás Ripoll (Hospital Son Llàtzer); Ramón Fernández Cid (Hospital Fundació Mateu Orfila); Sebastián Roig, Marga Vilar, Bernardo García de la Villa (Hospital Manacor); Marta Generelo (Hospital de Inca); Iñaki Unzaga, Inma Prieto, Juana María Vidal (SAMU 061); Guillem Frontera (IdISPa). 
Special acknowledgments to Cristina Acedo Amer. Data Manager del registro CI-IB. Department of Cardiology of Hospital Universitario de Son Espases y IdiSBA

Departamento de Informátic of Hospital Universitario Son Llatzer Maria Ponseti: Antonio Hernández, Víctor Estrada y Toni Contestí

Departamento de Informatic (OTIC): Marc Sansalvador

\section{Authors'contributions}

Conceptualization:LS;Writing-original draft. GF; Data Analysis. TR and JT: Methodology. VP and MP; Hemodynamic Laboratory. AC, CR and MF:Supervision and Writing review. All authors read and approved the final manuscript.

\section{Funding}

The authors declare the non-existence of external funding for this article.

\section{Availability of data and materials}

The datasets used and/or analyzed during the current study are available from the corresponding author on reasonable request.

\section{Ethics approval and consent to participate}

The Research Ethics Committee obviated the need for informed consent when dealing with anonymous records. A data dissociation procedure has been carried out with the aim of transforming them into anonymous and irreversibly dissociated, destroying any link or nexus that could identify the patient. At all times, the confidentiality of the information was maintained in accordance with the provisions of Organic Law 15/1999 of December 13, Protection of Personal Data, and Law 41/2002 of November 14, which regulates autonomy of the patient and the rights and obligations regarding information and clinical documentation. The new legislation in the EU on personal data has been applied, specifically Regulation (EU) 2016/679 of the European Parliament and of the Council of April 27, 2016 on Data Protection (RGPD).

\section{Consent for publication}

Not applicable

\section{Competing interests}

The authors have not received any financial aid to carry out this work. Nor have we entered into any agreement whereby we will receive benefits or fees from any business entity

\section{Author detalls}


${ }^{1}$ Intensive Medicine Service. Son Llàtzer University Hospital. Palma de Mallorca. Balearic Islands. Spain.

${ }^{2}$ Institute of Health Research of Palma ( IdISPa ). Son Espases University Hospital. Palma de Mallorca, Spain

${ }^{3}$ Department of Cardiology. Son Llàtzer University Hospital. Palma de Mallorca. Balearic Islands. Spain

${ }^{5}$ Department of Cardiology. Son Espases University Hospital. Palma de Mallorca. Balearic Islands. Spain

${ }^{6}$ Intensive Medicine Department. "Miguel Servet" University Hospital. Zaragoza

Spain.

\section{Bibliography}

1. Peral V, Carrillo A, Bethencourt A, Fiol M, Gómez-Jaume A, Alameda M, et al., Grupo de Trabajo del Registro Cl-IB. Código Infarto Illes-Balears. Modelo de intervención coronaria percutánea primaria en las Islas Baleares. Rev Esp Cardiol Supl.2011;11(C):35--43.

2. Socias L, Frontera G, Rubert C, Carrillo A, Peral V, Rodriguez A, et al. Análisis comparativo de 2 registros de infarto agudo de miocardio tras una década de cambios. Estudio IBERICA (1996-1998) y Código Infarto-Illes Balears (2008-2010). Med Intensiva. 2016;40 (9):541-549.

3. Reina A, Colmenero M, García C, Expósito M, Martín E, Bermúdez CL, et al. Diferencias en los resultados de la atención a los pacientes con síndrome coronario agudo con elevación del segmento ST (SCACEST) en función del acceso inicial a hospitales con o sin sala de hemodinámica en Andalucía. Emergencias 2014; 26: 101-108.

4. Ibanez B, James S, Agewall S, Antunes MJ, Bucciarelli-Ducci C, Bueno H, Caforio ALP, et I. 2017 ESC Guidelines for the management of acute myocardial infarction in patients presenting with STsegment elevation. Eur Heart J. 2018;39:119-177

5. Rothnie KJ, Quint JK. Chronic obstructive pulmonary disease and acute myocardial infarction: effects on presentation, management, and outcomes. Eur Heart J Qual Care Clin Outcomes. 2016;2(2):81-90.

6. Rothnie KJ, Yan R, Smeeth L, Quint JK. Risk of myocardial infarction (MI) and death following MI in people with chronic obstructive pulmonary disease (COPD): a systematic review and meta-analysis. BMJ Open 2015;5:e007824.

7. Aboal J, Núñez M, Bosch D, Tirón C, Brugada R, Loma-Oso P Angioplastia primaria frente a fibrinolisis en pacientes alejados de un centro con hemodinámica. Emergencias 2017;29:99-104.

8. Henriques JP, Zijlstra F, van't Hof AW, de Boer MJ, Dambrink JH, Gosselink AT, et al. Primary percutaneous coronary intervention versus thrombolytic treatment: Long term follow up according to infarct location. Heart. 2006;92:75--9 
9. Every NR, Larson EB, Litwin PE, Maynard C, Finn SD, Eisenberg MS, et al. The association between on-site cardiac catheterization facilities and the use of coronary angiography after acute myocarial infarction. Myocardial Infarction Triage and Intervention Project Investigators. N Engl J Med. 1993;329:546-51.

10. Alter DA, Naylor CD, Austin PC, Tu JV. Long-term MI outcome at hospitals with or without on-site revascularitation. JAMA. 2001;285:2101-8.

11. Van Brabandt $H$, Camberlin C, Vrijens F, Parmentier Y, Ramaekers D, Bonneux L. More is not better in the early care of acute myocardial infarction: a prospective cohort analysis on administrative databases. Eur Heart J. 2006;27:2649-54.

12. Henry TD, Sharkey SW, Burke MN, Chavez IJ, Graham KJ, Henry CR, et al. A regional system to provide timely access to percutaneous coronary intervention for ST-elevation myocardial infarction. Circulation. 2007;116:721-8

13. McNamara RL, Wang Y, Herrin J, Curtis JP, Bradley EH, Magid DJ, et al. Effect of Door-to-Balloon Time on Mortality in Patients With STSegment Elevation Myocardial Infarction. J Am Coll Cardiol.2006;47:2180-6.

14. Jollis JG, Al-Khalidi HR, Roettig ML, Berger PB, Corbett CC, Doerfler SM, et al. Impact of Regionalization of ST-Segment-Elevation Myocardial Infarction Care on Treatment Times and Outcomes for Emergency Medical Services-Transported Patients Presenting to Hospitals With Percutaneous Coronary Intervention Mission: Lifeline Accelerator-2. 2018;137:376-387

\section{Tables}

TABLE I. Demographic and clinical characteristics of the population 


\begin{tabular}{|c|c|c|c|}
\hline & Without EC & With EC & $\mathrm{p}$ \\
\hline Number of patients, n (\%) & $490(81)$ & $115(19)$ & \\
\hline Age, median (p25-75) & $59(51-69)$ & $66(53-77)$ & 0.008 \\
\hline Sex: male (\%) & $344(70.2)$ & $97(84.3)$ & 0.234 \\
\hline \multicolumn{4}{|l|}{ Pathological history, n (\%) } \\
\hline Smoker & $299(61.0)$ & $71(61.7)$ & 0,230 \\
\hline COPD & $28(5.7)$ & $17(14,8)$ & 0.001 \\
\hline Arterial hypertension & $241(49.2)$ & $82(71.3)$ & 0.211 \\
\hline Hyperlipidemia & $200(40.8)$ & $53(46,1)$ & 0.284 \\
\hline Mellitus diabetes & $122(24.9)$ & 38 ( 33.1 ) & 0.293 \\
\hline Previous infarction & $47(9.6)$ & $19(16.5)$ & 0.050 \\
\hline Previous angioplasty & $36(7.3)$ & $11(9.6)$ & 0.424 \\
\hline \multicolumn{4}{|l|}{ Previous treatment, $\mathrm{n}(\%)$} \\
\hline Aspirin & $98(20)$ & $43(37.4)$ & 0.456 \\
\hline Beta-blockers & $69(14.1)$ & $29(25.2)$ & 0.118 \\
\hline ARAII / IECAS & $154(31.4)$ & $59(51.3)$ & 0.060 \\
\hline Diuretics & $64(13.1)$ & $30(26.1)$ & 0.032 \\
\hline Insulin & $37(7.6)$ & $12(10.4)$ & 0.708 \\
\hline Oral antidiabetics & $66(13.5)$ & $31(27)$ & 0.524 \\
\hline Location (\%) & & & 0.007 \\
\hline Anterior & $197(40.2)$ & $83(72.2)$ & \\
\hline inferior & $232(47.3)$ & $25(21.7)$ & \\
\hline No specific & $61(12.5)$ & $7(6.1))$ & \\
\hline Killip on admission, $n$ (\%) & & & 0.001 \\
\hline $1+\|$ & $424(86.5)$ & $87(75.6)$ & \\
\hline III + IV & $66(13.5)$ & $28(24.4)$ & \\
\hline Reperfusion treatment, $\mathrm{n}(\%)$ & & & 0.024 \\
\hline Primary Angioplasty & $396(80.8)$ & $71(61.7)$ & \\
\hline Fibrinolysis & $37(7.6)$ & $16(13.9)$ & \\
\hline
\end{tabular}




\begin{tabular}{|llll|}
\hline Without revascularization & $57(11.6)$ & $28(24,4)$ & \\
\hline Action times, median (p25-p75) & & & \\
\hline Onset symptoms-FCM (fibrinolysis) & $99(50-161)$ & $45(29-145)$ & 0.170 \\
\hline door-to-needle time (fibrinolysis) & $43(28-77)$ & $30(20-67)$ & 0.801 \\
\hline Onset symptoms-FCM (Cl-IB) & $110(60-218)$ & $85(40-225)$ & 0.029 \\
\hline FCM- AP> 90 minutes & $75(63-97)$ & $84(65-110)$ & 0.070 \\
\hline Hospital stay & $6(4-8)$ & $7(7-11)$ & 0.789 \\
\hline
\end{tabular}

EC: cardiovascular event; COPD: chronic obstructive pulmonary disease. FCM: First medical contact; PA: Primary angioplasty. Cl_IB: Infarct Code-Illes Balears. FCM-AP. Time of first medical contact and start of primary angioplasty

TABLE II. Multivariate analysis of the cardiovascular event

\begin{tabular}{|lllll|}
\hline & HR & \multicolumn{2}{c|}{$95 \%$ Cl for HR } & p \\
\cline { 2 - 5 } & & lower & Higher & \\
\cline { 1 - 4 } Age & 1,031 & 1,013 & 1,048 & 0.001 \\
\hline COPD & 2,555 & 1,308 & 4,989 & 0.006 \\
\hline Symptoms-FCM onset time & 1,048 & 1,004 & 1,094 & 0.032 \\
\hline PCM-PA> 90 minutes & 1,787 & 1,120 & 2,852 & 0.015 \\
\hline Location & & & & \\
\hline Anterior & 1 & & & \\
\hline Inferior & 0.549 & 0.350 & 0.860 & 0.009 \\
\hline No specific & 0.246 & 0.030 & 1,992 & 0.189 \\
\hline Revascularization treatment & & & & \\
\hline Primary angioplasty & 1 & & & \\
\hline Fibrinolysis & 2,268 & 1,111 & 4,388 & 0.024 \\
\hline Without revascularization & 1,818 & 1,043 & 3,166 & 0.035 \\
\hline
\end{tabular}

HR: hazard ratio; 95\% Cl: 95\% confidence interval. COPD: chronic obstructive pulmonary disease. FCM: First medical contact. PA: Primary angioplasty. PCM-PA : start time of first medical contact and start of primary angioplasty 
TABLE III . Cox regression model of mortality at $\mathbf{3 0}$ days in patients who only received primary angioplasty .

\begin{tabular}{|lcccc|}
\hline & HR & \multicolumn{2}{c|}{$95 \%$ Cl for HR } & p \\
\cline { 3 - 4 } & & lower & Higher & \\
\hline Age & 1,070 & 1,037 & 1,105 & 0.001 \\
\hline COPD & 2,949 & 1,273 & 6,832 & 0.012 \\
\hline Symptoms-FCM onset time & 1,001 & 1,000 & 1,002 & 0.003 \\
\hline FCM-PA $>90$ minute & 1,835 & 0.922 & 3,650 & 0.084 \\
\hline
\end{tabular}

HR: hazard ratio; 95\% Cl: 95\% confidence interval. COPD: chronic obstructive pulmonary disease. FCM: First medical contact. FCM-PA : start time of first medical contact and start of primary angioplasty

\section{Figures}




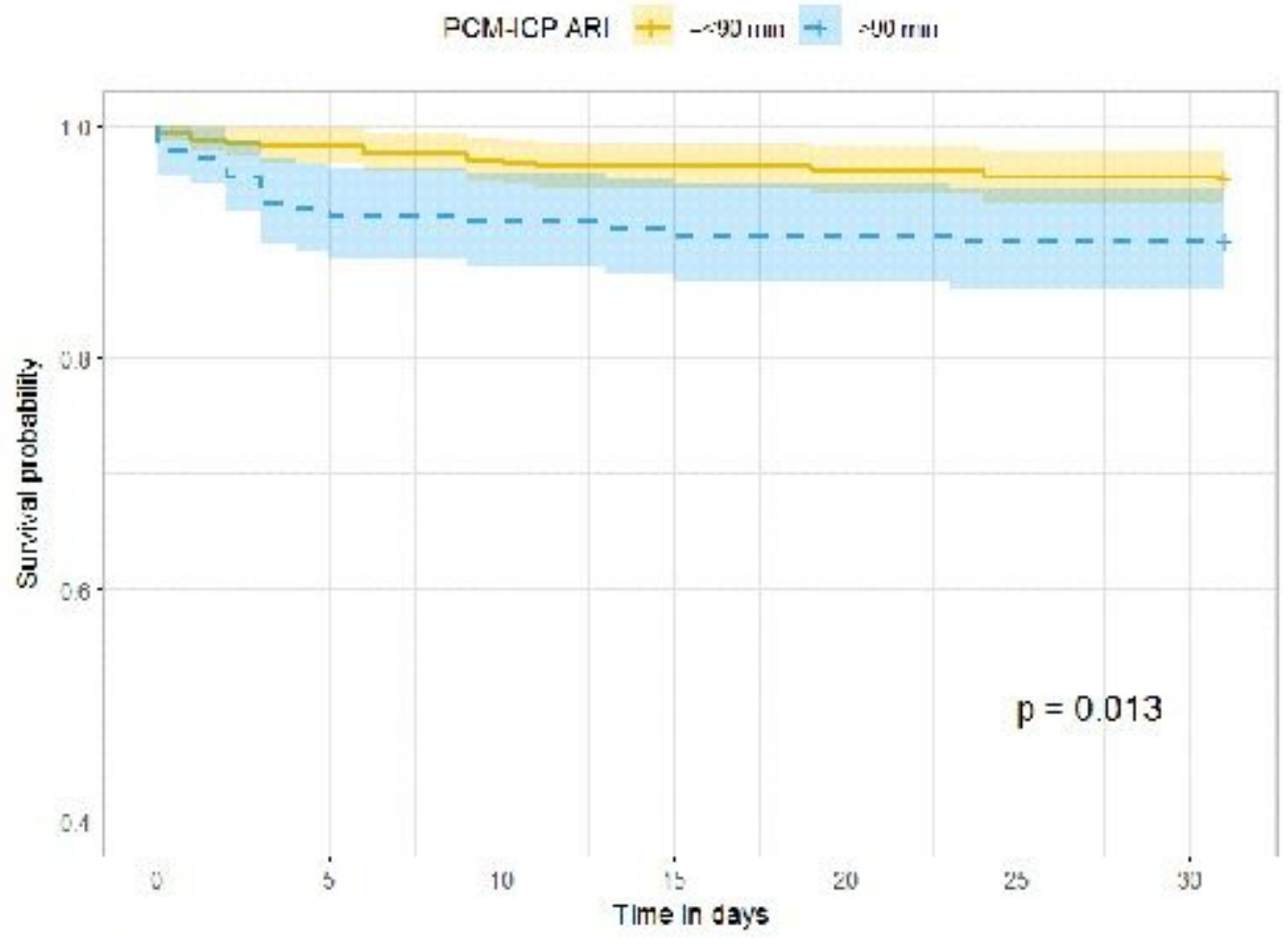

\begin{tabular}{|c|c|c|c|c|c|c|c|}
\hline \multirow{3}{*}{ 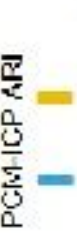 } & \multicolumn{7}{|c|}{ Number at risk } \\
\hline & 338 & 332 & 328 & 326 & 325 & 323 & 323 \\
\hline & 181 & 168 & 186 & 165 & 164 & 163 & 163 \\
\hline & 0 & 5 & 10 & Tlme in & 20 & 25 & 30 \\
\hline
\end{tabular}

FOM: First Contact Medical. PA Primary Angioplasty

Figure 1

Kaplan-Meier survival analysis at 30 days 